\title{
Contribuição da biópsia pulmonar a céu aberto na avaliação de pneumopatias difusas e agudas em unidade de terapia intensiva pediátrica*
}

\begin{abstract}
Albert Bousso ${ }^{1}$, Evandro Roberto BaldacCl ${ }^{2}$, José Carlos Fernandes ${ }^{3}$, IRACema de Cássia Oliveira Fernandes ${ }^{1}$, Andréa Maria Gomes CORdeIRO ${ }^{4}$, José Pinhata OTOCH ${ }^{5}$, Bernardo EjZEnBerg ${ }^{6}$, YassuhiKo OKaY ${ }^{7}$
\end{abstract}

Introdução: Os dados clínico-laboratoriais convencionais raramente fornecem o diagnóstico em pneumopatias difusas. 0 objetivo deste estudo foi avaliar o papel da biópsia pulmonar a céu aberto no que se refere ao seu potencial diagnóstico, ao impacto dos resultados sobre a conduta clínica e à incidência de complicações do procedimento. Material e métodos: No período de janeiro/1987 a janeiro/1997, 29 biópsias pulmonares foram realizadas em crianças com pneumopatias difusas, em insuficiência respiratória aguda, sem etiologia e sem resposta à terapêutica empírica prévia. Foram

excluídos os recém-nascidos, crianças com pneumopatias crônicas prévias e crianças com coagulopatia ou choque intratáveis. Todas as biópsias foram realizadas através de microtoracotomia no pulmão mais acometido ao exame radiológico. 0 fragmento de tecido pulmonar foi analisado por meio de culturas e de exames de microscopia ótica, eletrônica e imunofluorescência. Resultados: 0 processamento do material da biópsia forneceu pelo menos um diagnóstico histopatológico em todas as crianças estudadas (100\%) e em $20(68,9 \%)$ obteve-se um diagnóstico etiológico. Os principais diagnósticos histopatológicos foram: pneumonite intersticial não específica com fibrose variável em 18 casos; bronquiolite em oito casos e hipertensão pulmonar em três casos. Nos diagnósticos etiológicos,

os principais agentes foram: citomegalovírus em seis crianças; Pneumocystis carinii em três; adenovírus em três e infecção pelo vírus respiratório sincicial em três casos. Os resultados geraram mudanças no tratamento em 20 casos $(68,9 \%)$. As principais alterações de conduta foram a introdução de corticoterapia em 14 pacientes e a revisão da antibioticoterapia em seis. Sete casos

$(24,1 \%)$ apresentaram complicações, que foram resolvidas, e nenhum óbito foi relacionado ao procedimento. Conclusão: Conclui-se que a biópsia pulmonar a céu aberto é um procedimento que, mesmo invasivo, deve ser considerado na avaliação de crianças com pneumopatias difusas graves, sem etiologia definida, sem resposta à terapêutica previamente instituída e em insuficiência respiratória.

(J Pneumol 2002;28(1):30-40)

\section{Role of the open lung biopsy in the evaluation of undiagnosed acute lung disease in a pediatric intensive care unit}

Introduction: The diagnosis of diffuse lung disease is still a challenge for the pediatric intensive care physician. Routine clinical examinations and laboratory tests are frequently negative. The objective of this study was to evaluate the diagnostic potential, the impact on therapy and the rate of complications of open lung biopsy in children with undiagnosed diffuse lung disease, respiratory failure and inappropriate response to initial therapy. Methods: From J anuary 1987

* Trabalho realizado na Unidade de Terapia Intensiva Pediátrica do Hospital Universitário da Universidade de São Paulo.

1. Mestre em Pediatria; Médico Assistente da UTI Pediátrica.

2. Professor Livre-Docente.

3. Médico responsável pela UTI Pediátrica.

4. Médico Assistente da UTI Pediátrica.

5. Doutor em Cirurgia Torácica; Médico Assistente.
6. Doutor em Pediatria; Coordenador de Pesquisas da Divisão de Pediatria.

7. Professor Titular do Departamento de Pediatria; Diretor da Divisão de Pediatria.

Endereço para correspondência - Albert Bousso, Rua Dr. Gabriel dos Santos, 445/81 - 01231-011 - São Paulo, SP. Tel.: (11) 3825-7295; Fax: (11)3825-9952; e-mail: abousso@ intertrim.com.br

Recebido para publicação em 8/5/01. Aprovado, após revisão, em 29/11/01. 
to J anuary 1997, 29 children with diffuse pulmonary disease of unknown etiology, respiratory failure $\left(\mathrm{PaO}_{2} / \mathrm{FiO}_{2} \leq 300\right)$ and no response to previous treatments were considered for open lung biopsy. Newborns, children with known chronic pulmonary disease and children with untreatable shock or coagulopathy were excluded. All biopsies were performed by a thoracic surgeon by a microthoracotomy in the lung shown to be the most affected by $X$-ray examination. Tissue samples were analyzed in terms of cultures, light microscopy, electron microscopy and immunofluorescence microscopy, according to the pathologist's decision. Results: All biopsies (100\%) resulted in at least one histological diagnosis and in 20 patients (68.9\%) it was obtained a specific diagnosis. The most frequent histological patterns found were: non-specific interstitial

pneumonitis with variable degrees of fibrosis in 18 cases; bronchiolitis in eight cases and pulmonary hypertension in three cases. Regarding the most frequent specific diagnosis, six children were found with cytomegalovirus infection, three with Pneumocystis carinii, three with adenovirus and three with respiratory syncytial virus infection. These data induced a change in therapy in 20 children (68.9\%). The most frequent changes in therapy were the use of corticosteroids in 14 children and a review of the antibiotic regimen in six patients. Seven patients $(24.1 \%)$ presented with complications that were easily resolved. There were 13 deaths, probably due to the critical conditions of these patients, all unrelated to the procedure.

Conclusions: Open lung biopsy, though an invasive procedure, should be considered in the evaluation of selected children with undiagnosed diffuse lung disease, respiratory failure and with no satisfactory response to previous therapies.

Descritores - Biópsia pulmonar. Insuficiência respiratória. Doença pulmonar aguda. Crianças.

Key words - Lung biopsy. Respiratory failure. Acute lung disease. Children.

\section{INTRODUÇÃO}

As pneumopatias agudas associadas à insuficiência respiratória constituem uma condição clínica muito freqüente na faixa etária pediátrica, trazendo consigo morbimortalidade significativa e representando a principal causa de admissão em unidades de terapia intensiva pediátricas (UTIP). Nos Estados Unidos da América a insuficiência respiratória corresponde, segundo dados do Centro Nacional de Estatística em Saúde, à quarta causa mais comum de morte em lactentes ${ }^{(1)}$. No Brasil, não há dados estatísticos de âmbito nacional quanto à incidência de insuficiência respiratória aguda e ao impacto dessa situação clínica na morbimortalidade infantil. Ellovitch (2) cita que na unidade de terapia intensiva pediátrica do Hospital Infantil Menino J esus, em São Paulo, de um total de 887 admissões consecutivas no período de julho de 1987 a janeiro de 1991, a insuficiência respiratória foi o motivo da internação em 387 casos $(43,6 \%)$ e a responsável direta pelo óbito em 95 casos $(10,7 \%$ do total de internações ou $39,2 \%$ do total de óbitos no período).

$\mathrm{Na}$ Unidade de Terapia Intensiva Pediátrica do Hospital Universitário da Universidade de São Paulo os casos admitidos por problemas respiratórios corresponderam a uma média de $40,0 \%$ das admissões, conforme o Anuá-
Siglas e abreviaturas utilizadas neste trabalho

$\mathrm{FiO}_{2}$ - Fração inspirada de oxigênio

HIV - Vírus da imunodeficiência humana

$\mathrm{PaO}_{2}$ - Pressão arterial de oxigênio

UTIP - Unidade de terapia intensiva pediátrica

rio Estatístico da Divisão de Pediatria do Hospital Universitário da Universidade de São Paulo (2000)*. A média das taxas de mortalidade da Unidade de Terapia Intensiva Pediátrica, nos anos de 1992 a 2000, foi de $6,7 \%$, ao passo que a média das taxas de mortalidade devidas a quadros respiratórios foi de $21,2 \%$.

As pneumopatias agudas, quer alveolares, quer intersticiais, ainda representam enorme desafio para o pediatra, uma vez que são decorrentes de grande número de possibilidades diagnósticas, que o diagnóstico etiológico definitivo é de difícil confirmação e que a via respiratória baixa é de difícil acesso à investigação clínica(3).

Os pacientes imunodeprimidos constituem um grupo especial. Nessas crianças é imperativo que se faça um diagnóstico rápido, seguro e específico, a fim de instituir o mais precocemente possível a terapêutica mais apropriada e, conseqüentemente, obter um prognóstico meIhor. Dichter et al. ${ }^{(4)}$ ressaltam que o paciente imunocomprometido, além de ser mais suscetível a infecções por germes comuns e oportunistas, tem apresentação clínica

\footnotetext{
* Publicação interna do Departamento de Pediatria do Hospital Uni-
versitário da USP.

Publicação interna do Departamento de Pediatria do Hospital Uni-
versitário da USP.
} 
muitas vezes atípica e rapidamente progressiva. Nesses casos, a pesquisa diagnóstica deve ser a mais completa e precoce possível, mesmo que os sintomas possam parecer pouco intensos.

Apesar do avanço nas técnicas de investigação, o diagnóstico das pneumopatias agudas é freqüentemente difícil, pois o quadro clínico desses doentes é raramente elucidativo, assim como são pouco esclarecedores os métodos de diagnóstico não invasivos, quais sejam, a avaliação radiográfica, a hematimetria, as culturas de sangue e secreções respiratórias e os estudos sorológicos ${ }^{(3)}$. Fang et al.(5) acreditam que a pesquisa diagnóstica não-invasiva permite estabelecer 0 agente etiológico em menos de $50 \%$ dos pacientes.

Diante desse dilema, o clínico geralmente se depara com duas linhas de raciocínio possíveis. A primeira alternativa é fazer um diagnóstico etiológico presuntivo. Essa escolha geralmente significa dirigir a terapêutica para uma abordagem empírica, que inclui antibioticoterapia de largo espectro, além de ignorar os diagnósticos não infecciosos. Habitualmente, essa estratégia também implica em inicialmente excluir os germes oportunistas como possibilidade etiológica e obviamente incorre nos riscos dos efeitos colaterais de uma poliantibioticoterapia inespecífica. A segunda opção baseia-se, também de início, numa pesquisa etiológica não invasiva, com a instituição de um tratamento empírico, mas com a proposta de rapidamente caminhar para a realização de um procedimento invasivo com vistas a formular um diagnóstico mais preciso e, conseqüentemente, determinar a terapêutica mais adequada.

Outro problema comum aos pacientes admitidos em unidades de terapia intensiva, especialmente aqueles submetidos à ventilação mecânica, é a possível ocorrência de infecção nosocomial. Lode et al.(6) citam que a pneumonia nosocomial ocorre em 9 a $21 \%$ dos pacientes ventilados, chegando a mais de $70 \%$ nos acometidos pela síndrome do desconforto respiratório agudo. A pneumonia hospitalar associada à ventilação mecânica é a principal causa de mortalidade por infecção hospitalar nos Estados Unidos da América ${ }^{(7)}$. Fagon et al. ${ }^{(8)}$, num estudo de caso-controle, encontraram taxa de mortalidade de $54,2 \%$ para os pacientes que apresentavam pneumonia associada à ventilação mecânica e de $27,1 \%$ no grupo controle. 0 diagnóstico etiológico da pneumonia hospitalar associada à ventilação mecânica é também muito difícil, freqüentemente necessitando de pesquisa diagnóstica com métodos invasivos para a sua definição.

Atualmente, vários métodos diagnósticos invasivos utilizados em adultos apresentam uso potencial para pacientes pediátricos, entre eles a punção pulmonar transtorácica, a biópsia transbrônquica, o lavado broncoalveolar e a biópsia pulmonar a céu aberto.
Todos esses procedimentos têm considerações especiais no que se refere ao seu uso em crianças. A punção pulmonar transtorácica tem hoje papel muito limitado na prática clínica pediátrica. Isso decorre do fato de que ela está contra-indicada para pacientes submetidos à ventilação mecânica, que o procedimento tem taxa considerável de complicações, tais como o pneumotórax e as hemorragias, que a sensibilidade do método está na faixa de $60 \%$ e que essa técnica não permite a avaliação histológica do material obtido.

Com o desenvolvimento da broncoscopia nos últimos 20 anos, surgiram novas possibilidades para o diagnóstico etiológico das doenças pulmonares alveolares e intersticiais, como a biópsia transbrônquica. Novamente, tendo em vista a baixa positividade de diagnóstico e 0 alto risco de complicações, a biópsia transbrônquica tem papel muito restrito na abordagem de crianças com quadros pulmonares graves.

O lavado broncoalveolar tem como proposta permitir a investigação das vias aéreas distais. $A$ interpretação dos resultados do lavado, entretanto, pode ser difícil, especialmente no caso da análise citopatológica. Apesar disso, a experiência clínica com o uso do lavado broncoalveolar em adultos é bastante extensa e hoje este é o méto do invasivo mais comumente utilizado para avaliar a via aérea distal em pacientes adultos com pneumopatias agudas.

À semelhança dos outros métodos invasivos já descritos, o lavado broncoalveolar tem utilidade ainda limitada na prática clínica pediátrica. A principal razão para esse fato é que até recentemente não se dispunha de padronização, tanto para a técnica de coleta quanto para a interpretação dos dados relativos à celularidade. Em conseqüência, o lavado broncoalveolar, ainda que promissor, não tem até o momento justificativa suficiente para o seu uso rotineiro, mesmo para os casos graves.

A última possibilidade de método invasivo para a exploração diagnóstica do tecido pulmonar é a biópsia pulmonar a céu aberto.

0 primeiro relato do uso desse recurso diagnóstico em crianças foi feito por Stringer et al.(9), que avaliaram 16 crianças de quatro meses a 16 anos. Atualmente, já há relatos do uso da biópsia pulmonar a céu aberto no período neonatal, mesmo para prematuros de muito baixo peso(10,11). Evidentemente, a experiência pediátrica é bem menor que a experiência em adultos, mas os dados disponíveis na literatura já permitem apreciação da aplicabilidade do método em crianças.

Vários autores têm confirmado que a técnica é exequível em crianças, demonstrando a sua utilidade no elucidamento diagnóstico nas pneumopatias difusas e comprovando incidência de complicações comparável à das casuísticas de adultos ${ }^{(12-22)}$. Esses mesmos autores não têm 
conseguido determinar se a biópsia realmente altera as elevadas taxas de mortalidade encontradas nesses pacientes.

Também no Brasil, Sakane et al.(23) descreveram a primeira casuística pediátrica do uso da biópsia pulmonar. Relataram os resultados de sete biópsias em seis crianças portadoras de insuficiência respiratória grave. 0 método revelou-se útil e permitiu mudança na conduta terapêutica em seis ocasiões. Concluíram que a biópsia a céu aberto é um procedimento seguro, que deve ser utilizado quando outros métodos menos invasivos falham no esclarecimento diagnóstico.

Com base no exposto acima, percebe-se que na faixa etária pediátrica, particularmente no lactente jovem menor de seis meses, o diagnóstico de pneumopatias agudas, difusas e graves ainda é um desafio a ser superado. Dentro das possibilidades disponíveis até o momento, a punção pulmonar transtorácica e a biópsia transbrônquica trazem consigo incidência de complicações muito alta, além de ser capazes de elucidar o diagnóstico em apenas 50 a $60 \%$ dos pacientes. 0 lavado broncoalveolar, embora tenha perspectiva de uso mais amplo, aguarda melhor padronização da análise citológica em crianças. Com isso, a biópsia pulmonar a céu aberto, que é considerada como procedimento "padrão ouro", com o qual se compara a eficácia de todos os outros métodos diagnósticos, é o método invasivo mais aceito na pesquisa de doenças pulmonares graves em crianças. Dentro dessa ótica, o propósito deste trabalho foi analisar o potencial diagnóstico da biópsia pulmonar a céu aberto na avaliação de crianças com pneumopatias agudas, difusas e graves; verificar o impacto do procedimento diagnóstico na conduta terapêutica; e determinar a incidência de complicações relacionadas ao procedimento.

\section{MATERIAL E MÉTODOS}

0 presente trabalho foi realizado na Unidade de Terapia Intensiva Pediátrica (UTIP) do Hospital Universitário da Universidade de São Paulo, que conta com seis leitos e dispõe de todos os recursos tecnológicos necessários para garantir atendimento de bom nível às crianças graves. $\mathrm{O}$ estudo foi aprovado pela comissão de ética em pesquisa do Hospital Universitário e para todos os casos foi obtido o consentimento informado junto aos pais ou responsáveis legais pela criança para a realização da biópsia pulmonar.

Foram incluídos todos os casos em que foi realizada a biópsia pulmonar a céu aberto, conforme os critérios de inclusão e exclusão, no período de janeiro de 1987 a janeiro de 1997.

Foram considerados para a realização da biópsia os pacientes que preencheram os seguintes critérios de in- clusão: processo pulmonar alvéolo-intersticial bilateral e difuso ao aspecto radiológico associado à insuficiência respiratória, determinada por uma relação pressão arterial de oxigênio/fração inspirada de oxigênio $\left(\mathrm{PaO}_{2} / \mathrm{FiO}_{2}\right)$ menor ou igual a 300; má resposta à terapêutica empírica instituída previamente e pesquisa etiológica prévia negativa.

Foram excluídos os recém-nascidos, pacientes com doença pulmonar crônica previamente conhecida, crianças portadoras de coagulopatias caracterizadas por sangramentos clínicos não responsivos à infusão de plasma fresco ou vitamina $\mathrm{K}$ e pacientes hemodinamicamente instáveis, com hipotensão não responsiva ao tratamento com fluidos e drogas vasoativas.

Previamente à biópsia, todos os pacientes seguiram uma sistemática de pesquisa etiológica que incluiu hemoculturas e culturas gerais para bactérias e fungos, sorologias para citomegalovírus, para o vírus da imunodeficiência humana, para Chlamydia trachomatis, para vírus respiratórios (adenovírus, vírus respiratório sincicial, influenza e parainfluenza), pesquisa de Pneumocystis carinii em secreção traqueal, e pesquisa de bacilo álcool-acidorresistente em secreção traqueal.

As biópsias foram realizadas no centro cirúrgico ou na própria unidade de terapia intensiva, seguindo as normas habituais de assepsia e anti-sepsia. 0 fragmento pulmonar foi obtido através de uma microtoracotomia no pulmão mais afetado ao exame radiológico. Após a retirada do material procedia-se à drenagem da cavidade pleural com um dreno tubular multiperfurado, exteriorizado por contra-abertura e conectado a um sistema fechado sob selo d'água.

0 fragmento de tecido pulmonar foi fracionado em subfragmentos, de modo a permitir o envio às diversas análises laboratoriais previstas. As amostras foram submetidas a análise microbiológica por meio de cultura bacteriana geral, cultura de fungos e cultura viral. Os espécimes reservados para análise histopatológica foram estudados por microscopia ótica, microscopia eletrônica, imunohistoquímica e imunofluorescência, de acordo com a decisão do patologista.

O controle de complicações constou da monitorização intra-operatória, quer no centro cirúrgico quer na unidade de terapia intensiva, com controle dos dados vitais, da oximetria de pulso e, eventualmente, da capnografia. Subseqüentemente, além da monitorização da oximetria, foram realizadas gasometrias seriadas a cada 12 horas com o registro periódico das condições do ventilador. Paralelamente foram obtidas radiografias de tórax a cada $12 \mathrm{~h}$ após a biópsia, por um período de $36 \mathrm{~h}$. Procedeu-se também ao controle do débito do dreno torácico em relação ao volume e ao aspecto das secreções e à presença de fístula aérea. Por fim, foram realizadas dosagens se- 
riadas a cada $6 \mathrm{~h}$ de hemoglobina e hematócrito, por um período de $36 \mathrm{~h}$.

A utilidade da biópsia pulmonar a céu aberto foi avaliada à luz dos dados de diagnóstico obtidos com o exame, do estudo da repercussão dos resultados sobre a conduta terapêutica, da correlação destes dados com a presença de complicações e da evolução final em termos de mortalidade.

\section{Resultados}

No período de janeiro de 1987 a janeiro de 1997, 29 crianças preencheram os critérios de inclusão, determinando um total de 29 biópsias pulmonares a céu aberto. Quinze eram do sexo masculino e 14 do feminino. A idade dos pacientes variou de um a 154 meses, com média de 11,6 meses e mediana de quatro meses. A maior parte das crianças era procedente do domicílio (23 casos), com seis casos transferidos de outros hospitais.

Os diagnósticos por ocasião da admissão mostraram alguma variabilidade, mas as doenças clínicas predominantes foram a broncopneumonia bilateral e a pneumonite intersticial. Os principais diagnósticos clínicos de admissão estão demonstrados na Tabela 1.

Observa-se que o número total de diagnósticos (44) é maior que 0 de pacientes, pois alguns doentes apresentavam mais que um diagnóstico.

No momento da indicação da biópsia, todas as crianças apresentavam-se em insuficiência respiratória, caracterizada por pressão arterial de oxigênio/fração inspirada de oxigênio $\left(\mathrm{PaO}_{2} / \mathrm{FiO}_{2}\right)$ média de 147,8 (variação de 52 a 282,5). Apenas quatro crianças não estavam sob ventilação mecânica no instante imediatamente antes à biópsia, sendo que as que foram submetidas a um supor-

TABELA 1

Diagnósticos clínicos por ocasião da admissão das 29 crianças submetidas à biópsia pulmonar a céu aberto

\begin{tabular}{lc}
\hline \multicolumn{1}{c}{ Diagnóstico de admissão } & № de casos \\
\hline Broncopneumonia bilateral & 13 \\
Pneumonite intersticial & 8 \\
Crises de apnéia & 6 \\
Bronquiolite & 5 \\
Diarréia aguda & 3 \\
Broncopneumonia aspirativa & 2 \\
Sepse & 2 \\
Cardiopatia congênita & 2 \\
Refluxo gastroesofágico & 1 \\
Síndrome hemolítico-urêmica & 1 \\
Leucemia linfóide aguda & 1 \\
Total & 44 \\
\hline
\end{tabular}

te ventilatório recebiam picos inspiratórios médios de $32,4 \mathrm{~cm}$ de água (variação de 22 a $55 \mathrm{~cm}$ ) e pressões expiratórias médias de $7,3 \mathrm{~cm}$ de água (variação de 4 a $12 \mathrm{~cm})$.

A apresentação da radiografia de tórax na fase prébiópsia foi muito semelhante em todo o grupo e constou basicamente do encontro de infiltrado alvéolo-intersticial difuso ou infiltrado intersticial difuso, como mostra a Tabela 2 .

A pesquisa etiológica que antecedeu a biópsia, realizada conforme a sistematização descrita na metodologia, resultou negativa, com exceção de cinco crianças que se mostraram soropositivas para o vírus da imunodeficiência humana. Estas foram submetidas a uma pesquisa complementar com o teste de Western-blot para anticorpos antivírus da imunodeficiência humana, que também resultou positiva.

Frente à dificuldade diagnóstica, à gravidade do quadro e à evolução insatisfatória, todas receberam multiantibioticoterapia de amplo espectro, tendo sido utilizadas duas a cinco drogas de uso simultâneo, inclusive com cobertura antifúngica.

A biópsia pulmonar foi realizada no Centro Cirúrgico em 27 casos e na Unidade de Terapia Intensiva em duas crianças. A biópsia foi executada em média no 19 으 dia de internação, variando do 30 ao $51^{\circ}$ dia. A análise temporal do momento da realização da biópsia mostra que, nos primeiros cinco anos, ela foi realizada, em média, no 20 으 dia de internação, no 19 o dia nos últimos cinco anos e no $12^{\circ}$ dia nos últimos três anos.

0 hemitórax direito foi o escolhido para a retirada do fragmento pulmonar em 17 ocasiões e o esquerdo nas 12 crianças restantes. Em todas foi colocado um dreno sob selo d'água após a biópsia e o tempo de drenagem foi de um a 11 dias, com média de 5,6 dias.

Todas as biópsias forneceram algum diagnóstico, quer etiológico, quer histopatológico. Nesse sentido, os dados resultantes dos diversos exames realizados nos fragmentos pulmonares foram agrupados em resultados que estabeleceram um diagnóstico etiológico ou um diagnóstico histopatológico.

TABELA 2

Característica radiográfica do tórax no momento da realização da biópsia pulmonar

\begin{tabular}{lc}
\hline \multicolumn{1}{c}{ Diagnóstico radiológico } & № de casos \\
\hline Infiltrado alvéolo-intersticial difuso & 15 \\
Infiltrado intersticial difuso & 9 \\
Velamento difuso bilateral & 3 \\
Infiltrado alvéolo-intersticial difuso + pneumotórax & 2 \\
Total & 29 \\
\hline
\end{tabular}


A pesquisa microbiológica através de culturas e de microscopia ótica possibilitou a confirmação do diagnóstico etiológico em 20 dos 29 pacientes $(68,9 \%)$.

A análise das culturas, embora útil, na maior parte das vezes permitiu confirmar diagnósticos que já haviam sido estabelecidos pela microscopia ótica. A cultura para bactérias revelou-se positiva em três ocasiões. Duas delas demonstraram crescimento de Klebsiella sp e uma foi positiva para Enterobacter aerogenes. Todas as outras culturas foram negativas, inclusive para bacilos álcool-acidorresistentes. As culturas para fungos mostraram-se invariavelmente negativas. Já nas culturas para vírus, obteve-se positividade maior. Das 29 culturas virais, em 11 houve crescimento, sendo cinco para citomegalovírus, três para adenovírus e três para vírus respiratório sincicial.

A microscopia ótica permitiu ainda o estabelecimento do diagnóstico etiológico em outras seis oportunidades. Em três pacientes verificou-se a presença de Pneumocystis carinii. Um paciente, cujas culturas virais foram negativas, apresentou as características histopatológicas e de imunohistoquímica positivas para citomegalovírus. Outro apresentava uma característica anatomopatológica típica de hemosiderose pulmonar, confirmada com a coloração específica de Perls. Por fim, houve uma criança com microscopia ótica diagnóstica de pneumonia intersticial aguda (síndrome de Hamman-Rich).

A Tabela 3 resume os diagnósticos etiológicos encontrados nas análises microbiológicas e histopatológicas.

Os estudos histopatológicos, além de estabelecer um diagnóstico etiológico em boa parte dos casos, forneceram pelo menos um diagnóstico histológico em todos os 29 pacientes. 0 principal deles foi a presença de pneumonite intersticial não específica com grau variável de fibrose em 18 casos. Seguiram-se os diagnósticos de bron-

TABELA 3

Diagnósticos etiológicos obtidos através das análises microbiológicas e histopatológicas

Diagnósticos etiológicos

№ de casos

Pneumonite aguda por citomegalovírus

6

Pneumonite aguda por Pneumocystis carinii

3

Infecção aguda por adenovírus

3

Infecção aguda pelo vírus respiratório sincicial

3

Infecção por Klebsiella sp

Infecção por Enterobacter aerogenes

Hemossiderose pulmonar

Pneumonia intersticial aguda

(síndrome de Hamman-Rich)

Total

20

quiolite em oito casos, hipertrofia da camada média das arteríolas pulmonares em três, alveolite aguda em três, broncodisplasia em dois, pneumonia bacteriana em dois, infiltrado eosinofílico em um e um último caso de pneumonite intersticial linfocitária. 0 número total de diagnósticos excede o de biópsias, pois alguns pacientes apresentaram mais que um achado histológico. A Tabela 4 reúne os diagnósticos histológicos encontrados.

A biópsia pulmonar determinou mudanças na orientação terapêutica em 20 dos 29 pacientes (68,9\%). A alteração de tratamento mais freqüente, presente em 14 casos, constou da introdução de corticoterapia na forma de pulsoterapia por três dias, seguida de dose de manutenção. Essa conduta tinha por objetivo tentar bloquear a formação de colágeno tipo I e, conseqüentemente, reduzir a fibrose irreversível. Outra conduta comum, adotada em face do resultado da biópsia, foi a reavaliação do esquema antibiótico, que ocorreu em seis pacientes. Outras três crianças foram iniciadas na terapêutica antiviral com ganciclovir, uma pôde começar o esquema de quimioterapia e uma última foi submetida à dieta de exclusão de leite de vaca para tratamento da hemosiderose. É importante ressaltar mais uma vez que o número total de mudanças de conduta é maior que o de pacientes, pois em algumas crianças a biópsia induziu mais de uma alteração no tratamento. Os dados descritos acima são apresentados na Tabela 5.

Com o seguimento pós-biópsia, sete pacientes apresentaram complicações $(24,1 \%)$, que podem ser divididas em achados radiológicos, complicações ventilatórias e complicações referentes a sangramentos. A avaliação radiológica seriada do tórax mostrou que em 28 das 29

TABELA 4

Achados histológicos nas 29 biópsias pulmonares a céu aberto

Achado histológico

№ de casos

Pneumonite intersticial não específica com fibrose

18

Bronquiolite

8

Hipertrofia da camada média das

arteríolas pulmonares

3

Alveolite aguda

3

Broncodisplasia

2

Pneumonia bacteriana

2

Infiltrado eosinofílico

1

Hemossiderose pulmonar

1

Pneumonia intersticial aguda

(síndrome de Hamman-Rich)

Pneumonite intersticial linfocitária

1

Total

1

40 
crianças não houve alteração da imagem pulmonar na fase imediatamente após a biópsia. Em um paciente foi possível observar piora do padrão de acometimento pulmonar no hemitórax direito, contralateral ao lado em que foi realizada a biópsia. Três apresentaram pneumotórax na retirada do dreno de tórax, sendo que um evoluiu com fístula aérea que perdurou até o óbito, oito dias após o procedimento.

Quanto ao grau de insuficiência respiratória, um paciente apresentou piora ventilatória, com aumento dos parâmetros do ventilador por um período de 24 horas.

0 controle seriado de hemoglobina demonstrou que três crianças tiveram sangramentos significativos e que necessitaram de transfusões de uma unidade de concentrado de glóbulos. A Tabela 6 resume as complicações encontradas nesta casuística.

Quanto à evolução final, o acompanhamento das crianças revelou taxa de mortalidade de 44,8\% (13 casos). Nenhum dos óbitos foi relacionado diretamente ao procedimento da biópsia e ocorreram, em média, no $13^{\circ}$ dia pós-biópsia, com mediana no 9 o dia pós-biópsia e variando de três a 36 dias após a biópsia.

\section{DISCUSSÃO}

0 presente estudo avaliou o papel da biópsia pulmonar a céu aberto em 29 crianças admitidas em uma unidade

TABELA 5

Mudanças na orientação terapêutica nos 29 pacientes submetidos à biópsia pulmonar a céu aberto

Tipo de mudança terapêutica com

№ de alterações base na biópsia pulmonar

Corticoterapia em forma de pulsoterapia

Revisão da antibioticoterapia

Introdução de ganciclovir

Suspensão do leite de vaca

Início de quimioterapia

Total de alterações

Obs.: As 25 mudanças de conduta ocorreram em 20 dos 29 pacientes $(68,9 \%)$.

TABELA 6

Complicações relacionadas à biópsia pulmonar

$$
\text { Complicação }
$$

№ de casos

Pneumotórax na retirada do dreno

Sangramento que necessitou de transfusão

Piora ventilatória por 24 horas

3

Total de terapia intensiva pediátrica. A casuística apresenta muitos aspectos semelhantes e algumas características que a diferenciam das principais séries pediátricas que se dedicaram ao assunto.

Inicialmente, observa-se que o número de biópsias realizadas neste trabalho é comparável ao dos trabalhos pediátricos mais expressivos ${ }^{(13-15,22,24,25)}$. É importante ressaltar, entretanto, que a maior parte desses trabalhos faz referência a pacientes com faixa etária extremamente ampla e chega a incluir pacientes de até 20 a 22 anos de idade. Os pacientes aqui avaliados, embora apresentassem faixa etária variando de um a 154 meses, concentraram-se na faixa de lactentes jovens, como mostra a mediana de quatro meses. Esse aspecto é o diferencial de nossa casuística, em relação à literatura, no que diz respeito à idade.

De outra parte, os diagnósticos de admissão freqüentemente diferem dos que haviam sido formulados antes da biópsia. Leijala et al.(13) mostraram que, em apenas 17 dos 33 doentes que estudaram, mantiveram-se os mesmos diagnósticos de admissão. No presente estudo, alguns pacientes tinham, por ocasião da admissão, diagnósticos que se modificaram ao longo da internação, mas a maior parte das crianças já havia sido internada por problemas respiratórios, pois dos 44 diagnósticos de admissão, apresentados pelas 29 crianças, 34 eram relacionados ao trato pulmonar.

0 desenho deste estudo previa que os pacientes incluídos estivessem em insuficiência respiratória aguda, definida pela presença de pressão arterial de $\mathrm{O}_{2}$ sobre uma fração inspirada de $\mathrm{O}_{2}$ menor que 300 . Essa definição foi posteriormente referendada pela norma estabelecida pelo consenso americano/europeu em síndrome do desconforto respiratório agudo(26). Vinte e cinco dos 29 necessitaram de ventilação mecânica e estavam com suporte ventilatório elevado, definido pelos altos níveis das pressões inspiratórias e expiratórias. Esses aspectos, relativos à insuficiência respiratória, expressam a gravidade do quadro clínico desses pacientes, mas é nossa opinião que a necessidade de ventilação mecânica em alto grau não contra-indica a realização do procedimento. Essa opinião é endossada por outros autores, como Bond et al.(18), que realizaram a biópsia em pacientes com insuficiência respiratória extrema e submetidos à oxigenação de membrana extracorpórea. Igualmente, Kornecki e Shemie ${ }^{(22)}$ executaram a biópsia apenas em crianças com insuficiência respiratória grave, também definida como $\mathrm{PaO}_{2} / \mathrm{FiO}_{2}$ $<300$, e concluíram que, apesar da elevada morbidade do procedimento neste grupo de pacientes, é um recurso diagnóstico bastante útil.

A par das condições ventilatórias, a abordagem dos pacientes com infiltrado pulmonar difuso e com insuficiência respiratória grave quase sempre envolve o uso de 
terapêuticas empíricas prévias; espera-se que grande parte dos candidatos à biópsia já tenha recebido múltiplos esquema antibióticos. Vários autores têm confirmado essa observação ${ }^{(16,25,26)}$, que também se faz presente nesta investigação, tendo havido extenso uso de antibióticos de largo espectro. Todos os pacientes usaram de duas a cinco drogas simultaneamente, sem, entretanto, apresentar nenhum sinal de melhora clínica ou radiológica. A utilização dessas drogas não teve qualquer implicação na indicação da biópsia.

Deve-se, também, fazer uma análise do padrão radiológico no momento da indicação da biópsia, que é variável conforme o autor estudado. Hewitt et al.(12) objetivaram estudar a biópsia em crianças com doença pulmonar difusa. A descrição dos dados radiológicos, entretanto, mostra que os autores incluíram nos 24 casos analisados, desde consolidações localizadas até infiltrados alvéolo-intersticiais bilaterais. Já Fan et al.(25) mostraram que, das 48 crianças por eles estudadas, 36 apresentavam infiltrados predominantemente intersticiais, seis tinham infiltrados alvéolo-intersticiais, quatro infiltrados alveolares e duas alterações inespecíficas. Izraeli et al.(17) empenharam-se em estudar 16 biópsias em 14 pacientes com infecção pelo vírus da imunodeficiência humana. Todas as imagens radiológicas eram compatíveis com infiltrados retículo-nodulares localizados (sete) ou infiltrados intersticiais difusos (sete). A nossa casuística foi essencialmente composta por crianças com infiltrados alvéolo-intersticial e intersticial difusos em 26 casos e opacificação difusa dos campos pulmonares em dois.

Para ter maior segurança na obtenção de uma amostra significativa, os autores são unânimes em afirmar que o fragmento de tecido pulmonar deve ser retirado da área pulmonar mais afetada ao exame radiológico, podendo haver, por motivos de ordem técnica, alguma preferência pelo pulmão esquerdo, caso o acometimento seja simétrico ${ }^{(12-14,16-18,22,23)}$. Os pacientes ora estudados quase invariavelmente apresentavam infiltrado alvéolo-intersticial difuso e a nossa orientação também baseou-se na retirada do tecido pulmonar do pulmão aparentemente mais lesado, respeitando a vontade do cirurgião torácico. Com esse princípio, observamos que houve pequeno predomínio do hemitórax direito (17 casos) sobre o esquerdo (12 casos).

A relevância do estado imunitário do paciente a ser submetido à biópsia ainda é objeto de grande debate. A maioria dos trabalhos, na área pediátrica, não faz distinção com relação a esse aspecto e inclui tanto os imunocomprometidos quanto os imunocompetentes ${ }^{(9,12,13,15,18 \text {, }}$ 19,21,24,29), não observando diferenças no potencial diagnóstico ou na freqüência de complicações da biópsia nestes dois tipos de doentes. Alguns procuraram avaliar a utilidade da biópsia em pacientes imunodeficientes ${ }^{(14,16,17)}$.
A conclusão desses estudos é de que a biópsia é um instrumento extremamente valioso para a obtenção do diagnóstico específico em crianças com infiltrados pulmonares difusos. Poucas são as casuísticas exclusivamente de pacientes pediátricos imunocompetentes. Fan et al. ${ }^{(25)}$, em trabalho retrospectivo pediátrico, incluíram, ao longo de 12 anos, 48 biópsias em crianças sem deficiências imunitárias. A positividade de diagnóstico da biópsia foi de $80 \%$, comparável, portanto, aos resultados obtidos em crianças imunodeficientes. Os mesmos autores, em um segundo trabalho, apresentam os resultados da biópsia em 15 crianças imunocompetentes, encontrando diagnósticos específicos em oito doentes $(53,3 \%)^{(30)}$.

0 presente estudo não tinha por objetivo a discriminação do estado imunitário mas, mesmo assim, identificouse uma criança com leucemia linfóide aguda e cinco crianças com sorologia positiva para HIV e, embora a infecção por esse vírus não tivesse sido comprovada com testes para a pesquisa de antígenos virais, todas as crianças apresentavam dados epidemiológicos e clínicos compatíveis com a síndrome da imunodeficiência adquirida. Os resultados das biópsias mostraram-se úteis, independentemente do estado imunitário.

Do ponto de vista técnico, existem ainda algumas dúvidas que precisam ser melhor respondidas. Uma das questões mais debatidas é relacionada ao momento ideal para realizar o procedimento. Idealmente, a biópsia deve ser executada de maneira que permita um diagnóstico específico precoce e em tempo de evolução em que o processo fibroproliferativo, reparativo, ainda seja reversível. Autores como Shimosato e Miller ${ }^{(31)}$ descrevem que, do ponto de vista histológico, dependendo do momento em que a biópsia é realizada, é possível encontrar alterações compatíveis com as fases exsudativa, proliferativa e fibrótica do dano alveolar difuso. Ressaltam ainda que nas fases iniciais é possível observar edema e formação de membranas hialinas que, nas fases mais tardias, podem ser incorporados ao processo de espessamento do interstício. $\mathrm{Na}$ fase intermediária, o interstício é difusamente expandido à custa de uma combinação de vários fatores que incluem 0 acúmulo de células mononucleares, o edema, a proliferação de fibroblastos e de pneumócitos tipo II. No estágio final, verifica-se que a fibrose promove completa desorganização da arquitetura pulmonar. Todo o processo pode tomar de sete a 21 dias para se instalar ${ }^{(32-}$ 34).

Isso posto, fica claro que a biópsia será pouco útil se realizada quando a lesão já progrediu totalmente para fibrose. Nesse sentido, é necessário que a abordagem de crianças com pneumopatias difusas e graves seja sempre sistematizada e ágil para que a decisão de realizar ou não a biópsia possa ser tomada em tempo hábil. Warner et al.(27), estudando 80 pacientes adultos e pediátricos, con- 
seguiram executar o procedimento em média 5,6 dias após o início do quadro respiratório. Prober et al.(14), por outro lado, realizaram 46 biópsias em média com sete dias (variação de zero a 30 dias). Bond et al.(18) também puderam biopsiar os seus 16 pacientes com menos de 10 dias (média de 9,6 dias).

Durante os dez anos em que este estudo foi realizado, a biópsia foi executada em média no 190 dia de internação. Nos últimos três anos, entretanto, possivelmente em decorrência de melhor sistemática de atendimento, esse período foi reduzido para 12 dias. É provável que maior agilidade no processo de indicação e execução da biópsia, até sete dias de evolução, permita obter diagnósticos anatomopatológicos em fase cuja resposta à terapêutica seja possivelmente melhor. No nosso material, entretanto, apesar de os diagnósticos terem sido feitos com aproximadamente três semanas de evolução em média, os resultados encontrados permitiram mudanças de tratamento que claramente beneficiaram alguns doentes.

Ainda com relação à técnica, discute-se a necessidade da drenagem pleural após o procedimento e, nos casos em que é instituída, o tempo em que esta deve ser manti$\mathrm{da}^{(16,18)}$. No nosso trabalho, todos os pacientes foram drenados e a média de 5,6 dias de drenagem está de acordo com o esperado, diante do grau de insuficiência respiratória que apresentavam.

0 número e tipos de diagnósticos que a biópsia forneceu, neste estudo, são bastante semelhantes aos descritos por outros pesquisadores que avaliaram séries pediátricas. Já no fim da década de 60 , Stringer et al.(9) publicaram os resultados de seu estudo pioneiro e encontraram positividade de diagnóstico de $94 \%$ nas 16 biópsias que realizaram. Esses números foram reproduzidos por outros pesquisadores, inclusive em casuísticas neona-

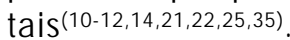

Todas as 29 crianças do nosso trabalho tiveram pelo menos um diagnóstico histopatológico, enquanto o diagnóstico etiológico foi confirmado em 20 dos 29 casos $(68,9 \%)$. Como descrito por outros autores(14,16), um diagnóstico histológico muito comum é o encontro de pneumonite intersticial com grau variável de fibrose, 0 que ocorreu em 18 das 29 crianças. Outro achado freqüente foi a presença de bronquiolite, fato que não surpreende, dada a característica etária desse grupo de crianças. É importante destacar que, em algumas vezes, o estudo histológico por si só já estabeleceu o diagnóstico final. É o caso da hemossiderose pulmonar e da pneumonia intersticial aguda (síndrome de Hamman-Rich).

Os principais agentes etiológicos identificados foram os virais (12/20), fato que também está de acordo com a literatura ${ }^{(16,18)}$. Os vírus identificados neste trabalho incluíram o citomegalovírus (seis), vírus respiratório sincicial (três) e adenovírus (três). Esses vírus são reconhecidamente cau- sadores de processos alvéolo-intersticiais graves no lactente jovem. Encontramos, ainda, a presença do Pneumocystis carinii, em três casos, fato que foi claramente coincidente com a sorologia positiva para HIV. Outro aspecto que chama a atenção é que, possivelmente em decorrência do uso prévio de antimicrobianos, o isolamento de agentes bacterianos foi feito em somente três casos. Por fim, vale ressaltar que, na maioria dos casos, os achados de microscopia ótica já foram capazes de fornecer a definição da doença.

0 impacto que os resultados obtidos com a biópsia têm sobre o esquema terapêutico é considerado por muitos autores como um fator essencial na avaliação da utilidade desse método de diagnóstico(9,14-16,22,25,36). Esses investigadores avaliam a biópsia como significativamente útil, capaz de induzir mudanças no tratamento de $43 \%$ a $77 \%$ das crianças estudadas. Para os ora apresentados, a biópsia determinou alteração de conduta em 20 das 29 crianças $(68,9 \%)$, dado comparável ao das casuísticas que tiveram melhor resultado nesse aspecto. A principal mudança terapêutica foi a introdução da corticoterapia na forma de pulsoterapia em 14 crianças. A diferença entre os 18 casos de pneumonite intersticial não-específica com fibrose, com os 14 submetidos à corticoterapia, denota a ocorrência de quatro casos em que a fibrose já estava plenamente instalada e em que não havia qualquer possibilidade de reversão. Outro aspecto digno de ser mencionado é que, embora tenha havido o isolamento de citomegalovírus em seis ocasiões, o uso do ganciclovir só ocorreu em três casos por conta da disponibilidade da droga no momento do diagnóstico. Por fim, é importante dizer que a definição de um diagnóstico tem um efeito muito positivo sobre a equipe médica, pois permite que se institua um tratamento específico com segurança.

De maneira geral, a biópsia pulmonar a céu aberto é tida como um procedimento relativamente seguro. Em adultos, são descritas taxas de complicação de 1,2\% a $56,0 \%$, conforme 0 autor estudado(26,37,38). Esses percentuais muito discrepantes são decorrentes das diferenças, dependendo do autor, na conceituação do que seja uma complicação. Na faixa pediátrica, a incidência é semeIhante e são descritas taxas de zero a $45 \%(9,13,22)$. Surpreendentemente, as casuísticas neonatais de biópsia foram isentas de complicações ${ }^{(10,11)}$. As principais complicações descritas são o pneumotórax, a fístula aérea, a hemorragia e a infecção. No seguimento pós-biópsia das crianças aqui estudadas, encontramos sete com complicações, perfazendo uma taxa relativamente alta de $24,1 \%$ dos casos. Em análise mais detalhada, entretanto, verifica-se que um caso apresentou piora ventilatória por 24 horas, sem maiores conseqüências, o que poderia ter sido classificado como uma complicação menor. Dos três casos que evoluíram para pneumotórax após a retirada 
do dreno, um já apresentava um pneumotórax, do mesmo lado, na fase anterior à biópsia. É importante reiterar que nenhuma complicação foi o determinante direto do óbito de qualquer criança. É nossa opinião que, diante de um doente em que se esgotaram as opções de diagnóstico e de tratamento empírico, uma taxa de complicação, como a encontrada neste estudo, pode ser considerada aceitável, desde que as complicações sejam contornáveis.

A grande controvérsia que cerca a biópsia pulmonar a céu aberto é se este procedimento, com os dados diagnósticos que fornece e com as mudanças terapêuticas que induz, consegue alterar a taxa de mortalidade dos pacientes com pneumopatias difusas e graves. Em pacientes adultos, são referidas taxas de mortalidade de $3 \%$ a $70 \%(27,37)$. Essa grande variabilidade pode ser devida ao tipo de paciente estudado (pacientes imunocompetentes versus pacientes imunocomprometidos), à gravidade do quadro clínico no momento da biópsia (pacientes em insuficiência respiratória versus pacientes ambulatoriais) e ao momento da evolução da doença em que a biópsia foi realizada. Em crianças, Foglia et al.(16) encontraram mortalidade de $64 \%$ nos 26 pacientes imunodeprimidos que estudaram. Afirmam que essa elevada taxa de óbito poderia ter sido menor se a biópsia tivesse sido realizada mais precocemente. Bond et al.(18), por sua vez, referiram mortalidade de sete em oito crianças submetidas a oxigenação por membrana extracorpórea. Obviamente, esses eram pacientes muito graves, cuja mortalidade é previsivelmente elevada, mesmo com terapêutica adequada. Tais autores também sugerem que a opção pela pesquisa invasiva, como a biópsia pulmonar, deve ser feita de forma rápida, para obter sobrevida maior. Fan et al.(35) corroboram essa opinião, pois, na análise comparativa de métodos invasivos em 51 crianças por eles estudadas, os cinco óbitos observados ocorreram no grupo de 29 pacientes, que foram classificados como mais graves e que necessitaram da biópsia pulmonar para diagnóstico.

A mortalidade evidenciada na presente investigação também foi elevada. Treze das 29 crianças $(44,8 \%)$ foram a óbito em média no 13임 após a biópsia e com mediana no 9o dia após o procedimento. Esse fato mostra que não houve relação entre o procedimento e o óbito. É importante considerar que esses pacientes apresentavam-se muitas vezes em estado crítico, com elevado grau de insuficiência respiratória e grande necessidade de suporte de ventilação mecânica.

Considerando os efeitos colaterais dos antibióticos na seleção de patógenos e na infecção hospitalar, os efeitos deletérios da ventilação mecânica, a progressiva destruição pulmonar por diferentes mecanismos e agentes com o tempo, acreditamos que um recurso diagnóstico que permita redirecionar a terapêutica de forma consistente, não empírica, é importante. A literatura mostra, e o nos- so trabalho confirma, que a biópsia pulmonar a céu aberto tem cumprido bem esse papel. Reconhecemos, entretanto, que apesar de verificarmos que em alguns casos a biópsia pode ser descrita como o marco primordial que determinou uma evolução satisfatória, até o momento não é possível avaliar a eficácia desse procedimento quanto à redução da morbimortalidade de forma global. A biópsia pulmonar a céu aberto é um procedimento que, ainda que invasivo, deve ser considerado na avaliação de crianças com pneumopatias difusas, em insuficiência respiratória grave, sem etiologia definida e com má resposta à terapêutica empírica previamente instituída.

\section{REFERÊNCIAS}

1. Guyer B, Hoyert DL, Martin JA, Ventura SJ, MacDorman MF, Strobino DM. Annual summary of vital statistics - 1998. Pediatrics 1999; 104:1229-46.

2. Ellovitch MEF. Insuficiência respiratória aguda. In: Matsumoto $T$, Carvalho WB, Hirschheimer MR, eds. Terapia intensiva pediátrica. 2a ed. São Paulo: Atheneu, 1997;254-84.

3. Craven DE, Steger KA. Hospital-acquired pneumonia: perspectives for the healthcare epidemiologist. Infect Control Hosp Epidemiol 1997; 18:783-95.

4. Dichter JR, Levine SJ, Shelhamer JH. Approach to the immunocompromised host with pulmonary symptoms. Hematol Oncol Clin North Am 1993;7:887-912.

5. Fang GD, Fine M, Orloff J. New and emerging etiologies for community-acquired pneumonia with implication for therapy: a prospective multicenter study of 359 cases. Medicine 1990;69:307-16.

6. Lode HM, Schabeng T, Raffenberg M, Mauch H. Nosocomial pneumonia in the critical care unit. Crit Care Clin North Am 1998;14: 119-33.

7. Kollef $M H$, Silver P. Ventilator-associated pneumonia: an update for clinicians. Respir Care 1995;40:1130-40.

8. Fagon JY, Chastre J, Hance AJ, Montravers P, Novara A, Gilbert T. Nosocomial pneumonia in ventilated patients: a cohort study evaluating attributable mortality and hospital stay. Am J Med 1993;94:2818.

9. Stringer RJ, Stiles QR, Lindesmith GG, Meyer BW, J ones J C. Use of lung biopsy in diagnosis of pulmonary lesions in children. Am Surg 1968;34:810-2

10. Cheu HW, Lally KP, Clark R, Harrel S, Null D. Open lung biopsy in the critically III newborn. Pediatrics 1990;86:561-3.

11. Walsh WF, Stanley S, Lally KP, Stribley RE, Treece TP, McCleskey F, Nuli DM. Ureaplasma urealyticum demonstrated by open lung biopsy in newborns with chronic lung disease. Pediatr Infect Dis J 1991;10: 823-7.

12. Hewitt CJ, Hull D, Keeling JW. Open lung biopsy in children with diffuse lung disease. Arch Dis Child 1974;49:27-35.

13. Leijala M, Louhimo I, Londfors EL. Open lung biopsy in children with diffuse pulmonary lesions. Acta Pediatr Scand 1982;71:717-20.

14. Prober $C G$, Whyte $H$, Smith $C R$. Open lung biopsy in immunocompromised children with pulmonary infiltrates. AJ DC 1984;138:60-3.

15. Early GL, Williams TE, Kilman JW. Open lung biopsy. Its effects on therapy in the pediatric patient. Chest 1985;87:467-9.

16. Foglia RP, Shilyansky J, Fonkalsrud EW. Emergency lung biopsy in immunocompromised pediatric patients. Ann Surg 1989;210:90-2. 
17. Izraeli S, Mueller BU, Ling A, Temeck BK, Lewis LL, Chang R, Shad AT, Pass HI, Pizzo PA. Role of tissue diagnosis in pulmonary involvement in pediatric human immunodeficiency virus infection. Pediatr Infect Dis J 1996;15:112-6.

18. Bond BSJ, Lee DJ, Stewart DL, Buchino JJ. Open lung biopsy in pediatric patients on extracorporeal membrane oxygenation. J Pediatr Surg 1996;31:1376-8.

19. Steinberg R, Freud E, Bem-Ari J, Schonfeld T, Golinsky D, Mor C, Zer $M$. Open lung biopsy - Successful diagnostic tool with therapeutic implication in the critically ill paediatric population. Acta Paediatr 1998; 87:945-8.

20. Stefanutti D, Morais L, Fournet J C, J an D, Casanova J L, Scheinmann $\mathrm{P}, \mathrm{Blic} \mathrm{J}$. Value of open lung biopsy in immunocompromised children. J Pediatr 2000;137:165-71.

21. Jaklitsch $M T$, Linden BC, Braunlin EA, Bolman RM $3^{\text {rd }}$, Foker JE. Open-lung biopsy guides therapy in children. Ann Thorac Surg 2001; 71:1779-85.

22. Kornecki A, Shemie SD. Open lung biopsy in children with respiratory failure. Crit Care Med 2001;29:1247-50.

23. Sakane PT, Katayama DM, Freddi NA, Carvalho MF, Saldiva PH, Pillegi $F L$, Martins FRP, Tannuri U. Biópsia pulmonar a céu aberto em crianças para diagnóstico histopatológico de doença pulmonar difusa de evolução grave. Rev Assoc Med Bras 1987;33:7-10.

24. Adeyemi SD, Ein SH, Simpson J S, Turner P. The value of emergency open lung biopsy in infants and children. J Pediatr Surg 1979;14: 426-7.

25. Fan LL, Mullen AL, Brugman SM, Inscore SC, Parks DP, White CW. Clinical spectrum of chronic interstitial lung disease in children. J Pediatr 1992;121:867-72.

26. Bernard GR, Artigas A, Brigham KL, Carlet J, Falke C, Hudson L, Lami M, Legall JR, Morris A, Spragg R and the Consensus Committee. The American-European Consensus Conference on ARDS: Definitions, mechanisms, relevant outcomes, and clinical trial coordination. Am J Respir Crit Care Med 1994;149:818-24.
27. Warner DO, Warner MA, Divertie MB. Open lung biopsy in patients with diffuse pulmonary infiltrates and acute respiratory failure. Am J Respir Dis 1988;94:90-4.

28. Canver CC, Mentzer RM. The role of open lung biopsy in early and late survival of ventilator-dependent patients with idiopatic lung disease. J Cardiovasc Surg 1994;35:151-5.

29. Wilson NJ, Seear MD, Taylor GP, LeBlanc JG, Sandor GGS. The clinical value and risks of lung biopsy in children with congenital heart disease. J Thorac Cardiovasc Surg 1990;99:460-8.

30. Fan LL, Lung CL, Wagener JS. The diagnostic value of bronchoalveolar lavage in immunocompetent children with chronic diffuse pulmonary infiltrates. Pediatric Pulmonol 1997;23:8-23.

31. Shimosato $Y$, Miller RR. General approach to lung biopsy. In: Shimosato $Y$, Miller RR, eds. Biopsy interpretation of the lung. New York: Raven Press, Ltd, 1995;1-18.

32. Zapol WM, Trelstad RL, Coffey JW, Tsai I, Salvador RA. Pulmonary fibrosis in severe acute respiratory failure. Am J Respir Dis 1979; 119:547-54.

33. Fukuda Y, Ishizaki M, Masuda Y, Kimura G, Kawanami O, Masugi Y. The role of intraalveolar fibrosis in the process of pulmonary structural remodeling in patients with diffuse alveolar damage. Am J Pathol 1987; 126:171-82.

34. Meduri GU, Belenchia J M, Estes RJ, Wunderink RG, Torky ME, Leeper J $r$ KV. Fibroproliferative phase of ARDS. Clinical findings and effects of corticosteroids. Chest 1991;100:943-52.

35. Fan LL, Kozinetz CA, Deterding RR, Brugman SM. Evaluation of a diagnostic approach to pediatric interstitial lung disease. Pediatrics 1998; 101:82-5

36. Gurunangan $\mathrm{S}$, Lawson RA, J ones PH. Evaluation of the usefulness in open lung biopsies. Pediatr Hematol Oncol 1992;9:107-13.

37. Shah SS, Tsang V, Goldstraw P. Open lung biopsy: a safe, reliable and accurate method for diagnosis in diffuse lung disease. Respiration 1992; 59:243-6.

38. Trachiotis GD, Hafner GH, Hix WR, Aaron BL. Role of open lung biopsy in diagnosing pulmonary complications of AIDS. Ann Thorac Surg 1992;54:898-901. 